\title{
Preparation of Fullerene Polycrystalline Films on Different Substrates by Physical Vapor Deposition
}

\author{
Dong-Wei Yan ${ }^{1,2}$, Wei Liu ${ }^{1,2}$, Hao-Ze Wang ${ }^{1}$ and Chun-Ru Wang ${ }^{1, *}$ \\ ${ }^{1}$ Institute of Chemistry, Chinese Academy of Sciences, Beijing 100080, P. R. China \\ ${ }^{2}$ Graduate School of Chinese Academy of Sciences, Beijing 100039, P. R. China
}

Fullerene $\left(\mathrm{C}_{60}\right)$ films were prepared on $\mathrm{Si}$, ITO, and $\mathrm{Cu}$ substrates by the physical vapor deposition (PVD) method. It was observed that the morphology and structure of fullerene films strongly depend on the substrates. Along with the interactions between fullerenes and substrates increasing from ITO, $\mathrm{Si}$ to $\mathrm{Cu}$ substrate, $\mathrm{C}_{60}$ forms small polycrystalline grains, large polycrystalline grains and fullerene oligomers under the same experimental conditions. The irreversible $\mathrm{C}_{60}$ polymerization on $\mathrm{Cu}$ substrate is suggested to be catalyzed by the copper metal. [doi:10.2320/matertrans.48.700]

(Received November 20, 2006; Accepted February 16, 2007; Published March 25, 2007)

Keywords: fullerene, polycrystalline films, physical vapor deposition, substrate-depending

\section{Introduction}

Over the last ten years, the study of fullerene films has attracted extensively interests ${ }^{1-3)}$ due to their promising applications in various fields such as nanodevices, ${ }^{4,5)}$ optics, ${ }^{6-8)}$ electrochemistry ${ }^{9,10)}$ etc. Dozens of methods, ${ }^{9,11-17)}$ e.g., electrophoretical depositions, ${ }^{9)}$ solvent evaporation, ${ }^{11,12)}$ physical vapor deposition, ${ }^{13,14)}$ molecular-beam epitaxy, ${ }^{15)}$ layer-by-layer assembly, ${ }^{16}$ and Langmuir-Blodgett films ${ }^{17}$ ) etc., were developed to prepare the fullerene films, and the morphology and structure of these as-prepared films were characterized by STM, AFM, LEEDS, XRD, XPS and various other spectroscopic techniques.

Fullerene films are generally either in polycrystalline form or in fullerene cluster form, depending on the film preparation method. Especially, the choice of substrates plays a crucial role, for example, $\mathrm{C}_{60}$ epitaxial films are prepared with perfect layered substrates in the ultra-high vacuum conditions, ${ }^{18)}$ and polycrystalline films are prepared on highquality semiconductor or passivated surfactant-mediated substrates. ${ }^{13,14)}$ In fact, it is the fullerene-substrate interaction that determines the morphology and structures of fullerene films.

Since the interactions between $\mathrm{C}_{60}$ and most typical substrates have been studied by the STM technique, the substrates for fullerene deposition can be roughly classified as three catalogues based on the fullerene/substrate interactions, i.e., metals, metal oxides, and semiconductors. Among them, metal oxide substrates usually have the weakest fullerene-substrate interactions as they lack dangling bonds on the surface; semiconductor substrates such as $\mathrm{Si}$ (111) ranked the second for having a large number of dangling bonds on the surface. In this case, the mobility of $\mathrm{C}_{60}$ is largely reduced, though the $\mathrm{C}_{60}$-substrate interaction is still van der Waals' bonds and there are no charge transfers between the fullerenes and substrates. ${ }^{19,20)}$ Finally, metal substrates such as $\mathrm{Cu}$ plates have the strongest fullerene/ substrate interactions due to the essential electron transfers

*Corresponding author, E-mail: crwang@iccas.ac.cn; Fax: $(+86) 10$ 62652120 . between $\mathrm{C}_{60}$ and some sites of the substrate. ${ }^{21)}$

In this letter, we selected three typical substrates, i.e., the silicon, indium tin oxide (ITO) and copper, representing the semiconductor, the metal oxide, and the metal substrates to study the $\mathrm{C}_{60}$ film formation process. The results revealed that the fullerene-substrate interactions indeed affect the morphology and crystalline structure of $\mathrm{C}_{60}$ films.

\section{Experimental Details}

Figure 1 schematically depicts the PVD setup used in this study. The main compositions of the setup are a quartz tube that connects to a high-vacuum system, and a temperaturecontrolled furnace. In a typical synthesis, $20 \mathrm{mg} \mathrm{C}_{60}$ powders sample with $99.5 \%$ purity was put inside the quartz tube for sublimation. Three plates, i.e., Si [Si(111) single crystal, General Research Institute for Nonferrous Metals], $\mathrm{Cu}[\mathrm{Cu}$ polycrystalline plate, Beijing Tongxian Chemical Co.], and ITO (Southern China Glass Scientific Co., Beijing), were selected as substrates. The Si slices and ITO were washed with detergent, distilled water, alcohol, and acetone in turns. The $\mathrm{Cu}$ substrate surfaces were prepared by electrochemical polishing. The surfaces roughness of $\mathrm{Si}, \mathrm{Cu}$ and ITO substrates were characterized by SEM and AFM. It was revealed that the surfaces of either $\mathrm{Si}(111), \mathrm{Cu}$, or ITO substrates are flat in $\mathrm{nm}$ scale. After chemical cleaning, the

(2)

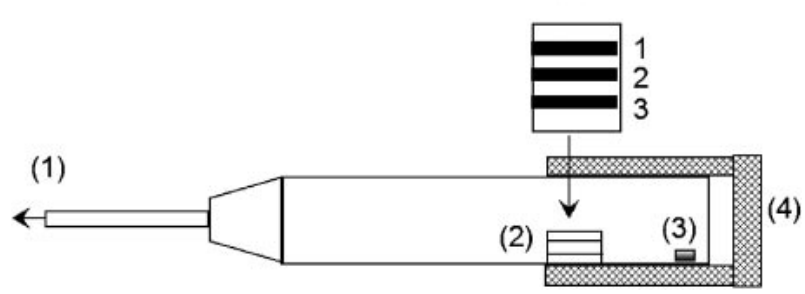

Fig. 1 Schematic diagram of the PVD setup. (1). Quartz tube connecting to vacuum system. (2). Deposition substrate holder and 3 substrates on the holder, in which substrate 1,2 , and 3 are $\mathrm{Si}(111), \mathrm{Cu}$, and ITO plates separately. (3). $\mathrm{C}_{60}$ powder. (4). Temperature-controlled furnace. 

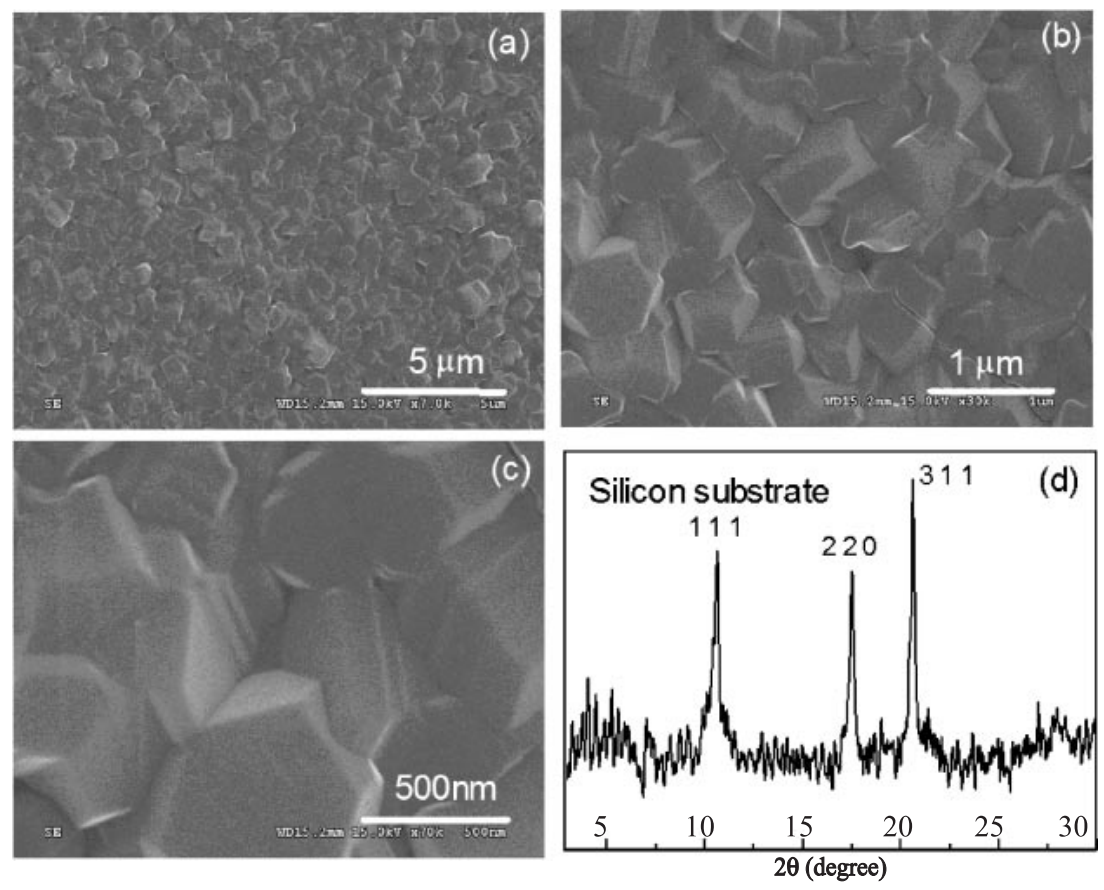

Fig. 2 SEM and XRD spectrometry study of the $\mathrm{C}_{60}$ deposition on $\mathrm{Si}(111)$ surfaces. (a), (b) and (c). SEM images of $\mathrm{C}_{60}$ film at different scales. (d). XRD pattern correspond to $\mathrm{C}_{60}$ film on $\mathrm{Si}$ surface.

substrates were put inside the quartz tube near the $\mathrm{C}_{60}$ source (ca. $5 \mathrm{~cm}$ ). As shown in the insert of Fig. 1, the three substrates were set parallel along the tube axial direction to maintain identical environments. Before experiments, both $\mathrm{C}_{60}$ and the substrates were first degassed in vacuum system $\left(10^{-3} \mathrm{~Pa}\right)$ for several hours, and then heated up the $\mathrm{C}_{60}$ with a temperature-controlled furnace (Tianjin Zhonghuan Co., China) for sublimation. The $\mathrm{C}_{60}$ sublimation temperature was set at $550^{\circ} \mathrm{C}$, and the substrates' temperature was measured between $350^{\circ} \mathrm{C}$ and $370^{\circ} \mathrm{C}$.

After 10 min. deposition of the $\mathrm{C}_{60}$ sample, the substrates showed black color, and the samples were analyzed by scanning electronic microscopy (SEM, Hitachi S-4300F) and XRD (Rigaku Dmax/rb diffractometer with $\mathrm{CuK} \alpha$ radiation, $\lambda=0.1542 \mathrm{~nm}, 40 \mathrm{kV}, 100 \mathrm{~mA}$ ) to characterize their morphology and structures.

\section{Results and Discussions}

Low $\mathrm{C}_{60}$ coverage on $\mathrm{Si}(111)$ was recently studied by Stimpel et al. ${ }^{20)}$ with STM technique. It was revealed that $\mathrm{C}_{60}$ molecules interact directly with the high density of dangling bonds on the $\mathrm{Si}(111)$ surface and lead to low $\mathrm{C}_{60}$ surface mobility, so fullerenes distribute disorderly in the first layer. After the $\operatorname{Si}(111)$ surface was passivated efficiently with the first layer of $\mathrm{C}_{60}$, the $\mathrm{C}_{60}$ surface mobility increases and ordered $\mathrm{C}_{60}$ crystalline structures are formed from the second layer. However, since the stress of first layer of $\mathrm{C}_{60}$ molecules acts on the upper $\mathrm{C}_{60}$ layers and prohibits long-range ordered $\mathrm{C}_{60}$ crystalline growth, many small islands of the ordered $\mathrm{C}_{60}$ crystalline structure were observed on the second $\mathrm{C}_{60}$ layers. Following the subsequent PVD process, these $\mathrm{C}_{60}$ islands grow along some preferential facets and forms many polycrystalline grains, as shown in Fig. 2.
In Fig. 2(a)-(c) the SEM images show clearly the regular polycrystalline pattern of the $\mathrm{C}_{60}$ film. The typical size of each $\mathrm{C}_{60}$ crystalline grain is ca. $0.5 \mu \mathrm{m}$. XRD is employed to determine the preferential growth orientation of the $C_{60}$ polycrystalline grains, and as shown in Fig. 3(d), the three main peaks in the XRD spectrum correspond to $\mathrm{C}_{60}$ (111), (220) and (311) planes. Because $\mathrm{C}_{60}$ single crystal exhibits only two types of morphological facets, ${ }^{22,23)}$ i.e., (111) and (200), the strong peaks of some high index facets (220) and (311) reveal the formation of $\mathrm{C}_{60}$ polycrystalline grains. The SEM and XRD results are consistent with each other. According to experimental process and XRD data analyses, the thickness of the film is about $100 \mathrm{~nm}$.

ITO is a typical electrode material for optoelectrochemistry and optoelectronics. Comparing with $\mathrm{Si}(111)$ substrate, ITO has no dangling bonds on the surface, so the fullerene/ substrate interactions for ITO should be much lower than that for silicon substrate. With the PVD of $\mathrm{C}_{60}$ molecules being performed on this substrate, the surface mobility of $\mathrm{C}_{60}$ would increase and the interaction between $\mathrm{C}_{60}$ molecules dominates the fullerene film formation, leading to larger $\mathrm{C}_{60}$ polycrystalline grains. As shown in Fig. 3(a), SEM study revealed that the typical fullerene grain size is ca. $1 \mu \mathrm{m}$.

XRD spectrum of this sample is shown in Fig. 3(b). It was observed that in this case the relative intensity of low index facet (111) to high facets (220) and (311) increases largely comparing with that on silicon surface. Moreover, it was observed that the peak line widths of $\mathrm{C}_{60}$ XRD spectrum in Fig. 3(b) are narrower than that in Fig. 2(d). According to the Scherrer equation:

$$
t(\operatorname{size})=\lambda /(\mathrm{B} \cdot \cos \theta)
$$

where $\mathrm{B}$ is the line width of the relevant XRD peaks, which is in reverse ratio to the polycrystalline size $t$. Therefore, the 


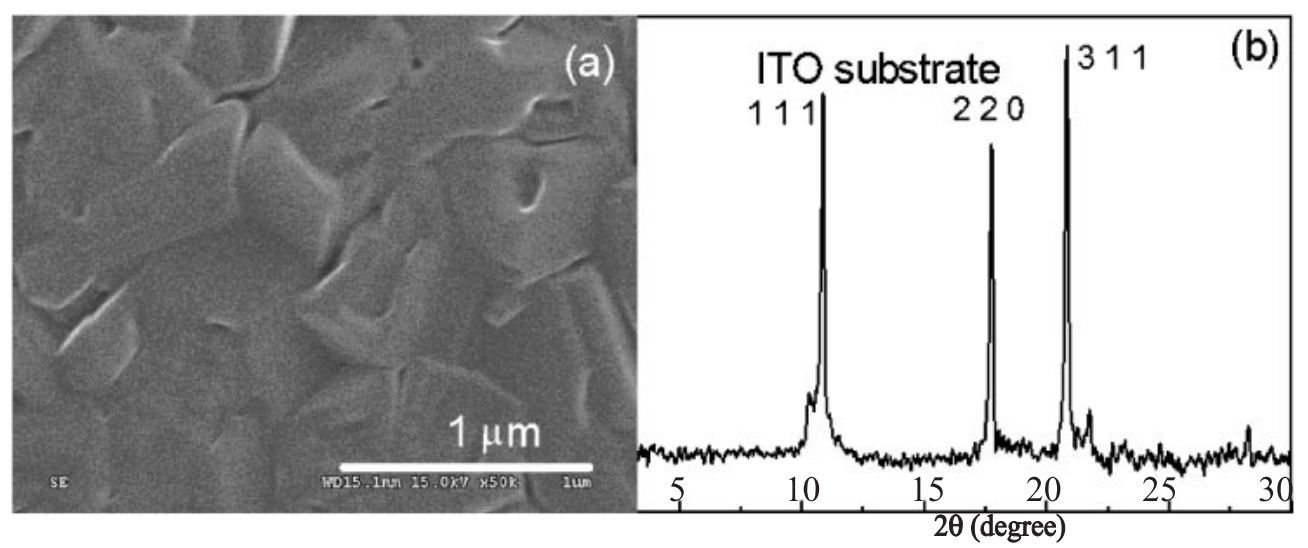

Fig. 3 SEM and XRD spectrometry study of the $\mathrm{C}_{60}$ deposition on ITO surfaces. (a). SEM images of $\mathrm{C}_{60}$ film. (b). XRD pattern correspond to $\mathrm{C}_{60}$ film on ITO surface.

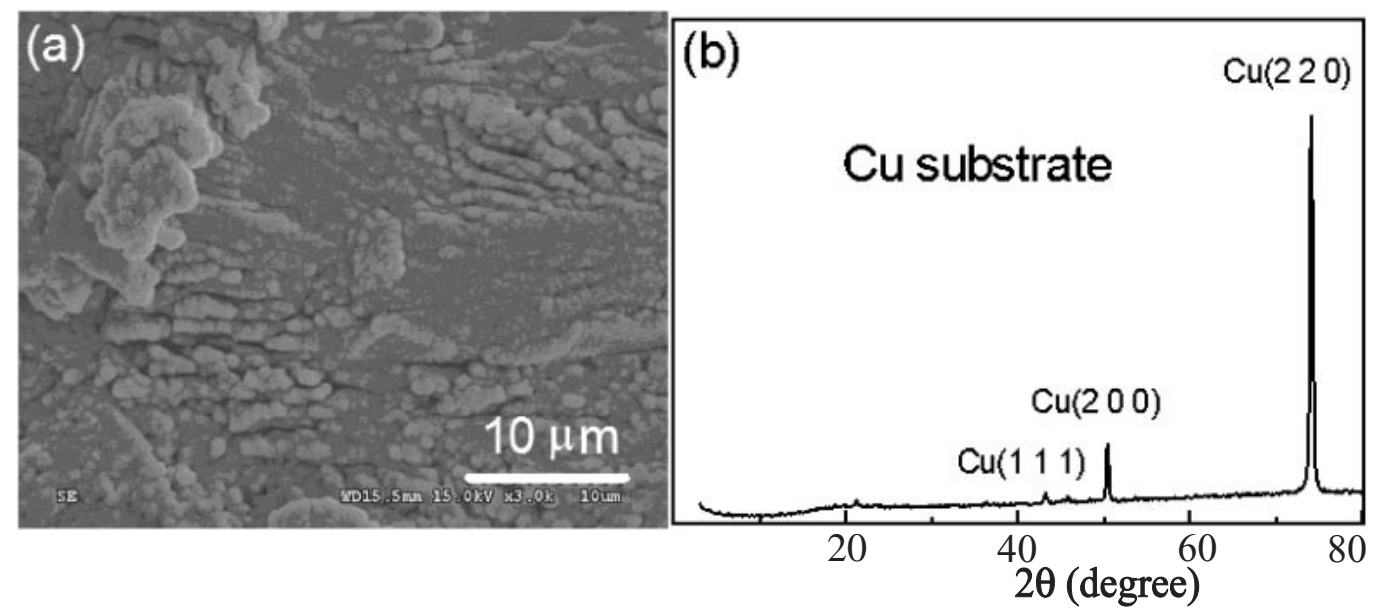

Fig. 4 SEM and XRD spectrometry study of the $\mathrm{C}_{60}$ deposition on $\mathrm{Cu}$ surfaces. (a). SEM images of the sample with $\mathrm{C}_{60}$ deposition on $\mathrm{Cu}$ surfaces. (b). XRD pattern correspond to $\mathrm{C}_{60}$ film on $\mathrm{Cu}$ surface, no $\mathrm{C}_{60}$ crystalline structure is observed.

$\mathrm{C}_{60}$ grain size on ITO substrate is larger than that formed on $\mathrm{Si}(111)$ substrate.

Above results clearly show that smaller fullerene-substrate interaction would lead to larger polycrystalline grains of $\mathrm{C}_{60}$. Next, we would like to see what's happen in the case of very strong substrate/fullerene interactions. As studied before, ${ }^{21)}$ the interaction between $\mathrm{C}_{60}$ and $\mathrm{Cu}$ substrate is so strong that would induce essential charge transfers from the $\mathrm{Cu}$ substrate to $\mathrm{C}_{60}$, i.e., ca. 1.6 electrons $/ \mathrm{C}_{60}$ molecule charge transfer was observed while $\mathrm{C}_{60}$ adsorbing on the terrace of $\mathrm{Cu}$ substrate. So a $\mathrm{Cu}$ plate was selected as the third substrate.

The SEM and XRD studies of $\mathrm{C}_{60}$ film depositing on $\mathrm{Cu}$ are shown in Fig. 4. Fascinatingly, no regular $\mathrm{C}_{60}$ morphology and polycrystalline structure were observed on the $\mathrm{Cu}$ substrate after the PVD process, even though the experimental conditions on $\mathrm{Cu}$ substrate are identical to that on ITO and silicon substrates. XRD spectrometry was performed and revealed that the lack of any $\mathrm{C}_{60}$ crystalline peaks too, so the $\mathrm{C}_{60}$ molecules were suggested to polymerize on the copper surface. To confirm the irreversible chemical reaction of $\mathrm{C}_{60}$ molecules on $\mathrm{Cu}$ substrate, the fullerene film was further treated up in toluene with sonication, and it is indeed that no any soluble $\mathrm{C}_{60}$ was found and the film remained on $\mathrm{Cu}$ plate, while the $\mathrm{C}_{60}$ films on ITO and $\mathrm{Si}$ substrates in parallel experiments were completely redissolvable in toluene. Moreover, laser desorption mass spectrometry study for the $\mathrm{C}_{60}$ films on $\mathrm{Cu}$ plate showed weak $\mathrm{C}_{60}$ peak, indicating that the basic structure of $\mathrm{C}_{60}$ is maintained. Therefore, $\mathrm{C}_{60}$ must be polymerized on the $\mathrm{Cu}$ substrate under current experimental conditions.

Note that in our experiment the measured substrates' temperature is only $350-370^{\circ} \mathrm{C}$, so it reminds us that copper must be an excellent catalyst for the $\mathrm{C}_{60}$ polymerizing reaction. We suggest that the charge transfers between $\mathrm{C}_{60}$ and substrate play a main role in the $\mathrm{C}_{60}$ polymerizing reactions. Further experiments are on progress to explore the catalyzing function of $\mathrm{Cu}$ in fullerene polymerizations.

\section{Conclusions}

$\mathrm{C}_{60}$ deposition on $\mathrm{Si}(111)$, ITO, and $\mathrm{Cu}$ substrates were studied by the physical vapor deposition technique. For $\mathrm{C}_{60}$ deposition on $\mathrm{Si}$ and ITO substrates, van der Waals interactions dominate the fullerene/substrate interactions and $\mathrm{C}_{60}$ molecules form polycrystalline structures, with the typical polycrystalline grain size being 0.5 and $1 \mu \mathrm{m}$ on $\mathrm{Si}$ and ITO substrates, respectively. For $\mathrm{C}_{60}$ molecules deposition on copper substrate, irreversible $\mathrm{C}_{60}$ polymerization was 
occurred under very low temperature $\left(350-370^{\circ} \mathrm{C}\right)$, suggesting that copper is excellent catalyst for $\mathrm{C}_{60}$ polymerizing reaction.

\section{Acknowledgements}

The authors thank NSFC (Nos. 50225206, 90206045, 20121301), the Major State Basic Research Program of China "Fundamental Investigation on Micro-Nano Sensors and Systems based on BNI Fusion" (Grant 2006CB300402).

\section{REFERENCES}

1) W. Kutner, P. Pieta, R. Nowakowski, J. W. Sobczak, Z. Kaszkur, A. L. McCarty and F. D'Souza: Chem. Mater. 17 (2005) 5635-5645.

2) P. Janda, T. Krieg and L. Dunsch: Adv. Mater. 10 (1998) 1434-1438.

3) I. M. Dmitruk, N. L. Dmitruk, E. V. Basiuk, J. G. Banuelos, A. Esparza and J. M. Saniger: Carbon 42 (2004) 1089-1093.

4) R. C. Haddon, A. S. Perel, R. C. Morris, T. T. M. Palstra, A. F. Hebard and R. M. Fleming: Appl. Phys. Lett. 67 (1995) 121-123.

5) C. P. Jarrett, K. Pichler, R. Newbould and R. H. Friend: Synth. Metal 77 (1996) 35-38.

6) Y. Matsuoka, N. Inami, E. Shikoh and A. Fujiwara: Sci Tech. Adv. Mater. 6 (2005) 427-430.

7) H. Hoppe and N. S. Sariciftci: J. Mater. Res. 19 (2004) 1924-1945.

8) Y. J. Yong, Y. L. Li, H. B. Liu, S. Wang, N. Wang, J. P. Zhuang, X. F. Li, X. R. He and D. B. Zhu: Nanotech. 16 (2005) 1899.

9) S. Barazzouk, S. Hotchandani and P. V. Kamat: Adv. Mater. 13 (2001)
1614-1617.

10) Y. M. Wang, P. V. Kamat and L. K. Patterson: J. Phys. Chem. 97 (1993) 8793-8797.

11) B. Miller, J. M. Rosamilia, G. Dabbagh, R. Tycko, R. C. Haddon, A. J. Muller, W. Wilson, D. W. Murphy and A. F. Hebard: J. Am. Chem. Soc. 113 (1991) 6291-6293.

12) S. Licht, O. Khaselev, P. A. Ramakrishnan, D. Faiman, E. A. Katz, A. Shames and S. Goren: Sol. Energ Mater. Sol Cells 51 (1998) 9-19.

13) R. S. Chen, Y. J. Lin, Y. C. Su and K. C. Chiu: Thin Solid Films 396 (2001) 103-108.

14) W. R. Cheng, S. J. Tang, Y. C. Su, Y. J. Lin and K. C. Chiu: J. Crystal. Growth 247 (2003) 401-407.

15) H. Sitter, M. T. Nguyen and D. Stifter: J. Cryst. Growth 174 (1997) 828-836.

16) Y. Liu, Y. Wang, H. Lu and R. O. Claus: J. Phys. Chem. B 103 (1999) 2035-2036.

17) C. Jehoulet, Y. S. Obeng, Y. T. Kim, F. M. Zhou and A. J. Bard: J. Am. Chem. Soc. 114 (1992) 4237-4247.

18) J. A. Dura, P. M. Pipenger, N. J. Halas, X. Z. Xiong, P. C. Chow and S. C. Moss: Appl. Phys. Lett. 63 (1993) 3443-3445.

19) A. V. Dunn, E. D. Stevensson and C. Dekker: Surf. Sci. 498 (2002) 237-243.

20) T. Stimpel, M. Schraufstetter and H. Baumgaertner: I. Eisele, Mater. Sci. Engineer. B89 (2002) 394-398.

21) C. Tindall, O. Takaoka, T. Kobayashi, Y. Hasegawa and T. Sakurai: Sci. Rep. Res. Inst. Tohoku Univ. Ser. A 44 (1997) 51-54.

22) M. A. Verheijin, H. Meekes, G. Meijer, E. Raas and P. Bennema: Chem. Phys. Lett. 191 (1992) 339-344.

23) K. Matsmoto, E. Schonherr and M. Wojnowski: J. Cryst. Growth. 135 (1994) 154-156. 